Research Article

\title{
The Impact of Fintech on Corporate Technology Innovation Based on Driving Effects, Mechanism Identification, and Heterogeneity Analysis
}

\author{
Jianwei Li $\mathbb{D}^{1},{ }^{1} \mathrm{Na} \mathrm{Li} \mathbb{D}^{1},{ }^{1}$ and Xiang Cheng $\mathbb{D}^{2}$ \\ ${ }^{1}$ School of Finance, Shandong Technology and Business University, Yantai 264003, China \\ ${ }^{2}$ School of Management, Beijing Union University, Beijing 100101, China \\ Correspondence should be addressed to Xiang Cheng; gltchengxiang@buu.edu.cn
}

Received 16 November 2021; Accepted 4 December 2021; Published 22 December 2021

Academic Editor: Daqing Gong

Copyright (c) 2021 Jianwei Li et al. This is an open access article distributed under the Creative Commons Attribution License, which permits unrestricted use, distribution, and reproduction in any medium, provided the original work is properly cited.

Fintech relies on emerging technologies such as artificial intelligence and big data to bring a new business model to the financial system; can this new change promote corporate technological innovation? To explore this question, this paper examines the possible impact mechanism of Fintech on enterprise technological innovation based on the examination of the impact of Fintech on enterprise technological innovation through a panel fixed effects model, using A-share listed enterprises in Shanghai and Shenzhen markets in China from 2011-2019, and further explores whether there is heterogeneity in this impact among enterprises with different traits. The results show that Fintech development can significantly promote firm technological innovation and that Fintech can influence firm technological innovation through two mechanisms: alleviating firm financing constraints and providing market opportunities for firms to enhance their profitability. In addition, the driving effect of Fintech on technological innovation is more pronounced in new firms, state-owned enterprises, and nonborrowed and listed firms. Based on the conclusion, it is proposed that the government should enhance certain policy support for Fintech guided by emerging technologies such as artificial intelligence, help Fintech empower the real economy, and at the same time promote the deep integration of Fintech and real enterprises, especially to strengthen the identification of Fintech for new enterprises and encourage stateowned enterprises to implement employee stock ownership system, as well as sound market construction to reduce barriers to listing of high-quality enterprises, so as to improve innovation policy effectiveness and provide a reference for the mitigation of enterprise innovation problems in the new situation.

\section{Introduction}

China is in a critical period of development transformation, economic structure optimization, and growth-driven transformation. In the report of the 19th Party Congress, Xi Jinping proposed to "deepen the reform of the financial system, enhance the capacity of financial services for the real economy," and promote innovative regulatory approaches. It was also pointed out that "innovation is the first driving force of development and is a strategic support for building a modern economic system." Although China has been making progress in innovation and reform, it lacks the capacity for independent innovation. The Fifth Plenary Session of the 19th Central Committee of People's Republic of China stated that "making science and technology selfreliance and self-improvement a strategic support for national development, we should adhere to the central position of innovation in the overall situation of China's modernization." As the main body of the national economy, the innovation drive of enterprises is the power source for them to maintain their competitive advantage and is a strong focus for improving China's comprehensive national power. However, the information asymmetry between banks and enterprises is a difficult shackle for China's financial system to empower the real economy and promote enterprise innovation at this stage.

With the development of frontier technologies such as big data, cloud computing, artificial intelligence, blockchain, 
and mobile Internet technology, traditional financial businesses and scenarios are constantly interacting and integrating with these frontier technologies to form a new financial industry. Fintech, with big data finance, artificial intelligence finance, blockchain finance, and quantitative finance as its core, has emerged, expanding the breadth and depth of financial services. Considering the relatively late start of Fintech, the existing literature mostly focuses on industrial policy $[1,2]$, market environment [3, 4], firm characteristics $[5,6]$, and corporate governance $[7,8]$ and other perspectives on how to influence corporate technological innovation; there is a lack of a more complete analytical framework and empirical findings regarding the Fintech-driven issues in corporate technological innovation. In this context, it is a realistic question to explore whether Fintech, which is characterized by high efficiency and low cost, can have a driving effect on corporate technology innovation.

The possible contributions of this paper are as follows: (i) Empirical means are used to enrich the research on the impact of Fintech on the innovation behavior of microentities of enterprises, adding empirical evidence to the topics related to Fintech and enterprise technological innovation. (ii) Based on the widespread application of artificial intelligence and big data technologies in the field of Fintech, this new mechanism that has an impact on the technological innovation of enterprises is proposed and tested. That is, Fintech creates market opportunities for firms by providing user-side scenario data, which in turn enhances their profitability. (iii) Through heterogeneity analysis, we further explore the differences in the impact of Fintech on the technological innovation of new and old enterprises, state-owned and non-state-owned enterprises, and backdoor-listed and IPO-listed enterprises and make further relevant policy implications.

\section{Literature Review}

2.1. Factors Influencing Business Innovation. With regard to the factors influencing corporate innovation, at the macrolevel, scholars have mainly studied the impact on corporate innovation in terms of national culture $[3,9]$, industrial policy $[1,2]$, and market environment $[3,4]$. At the microlevel, scholars have argued that factors such as firm characteristics, shareholding structure, and corporate governance have an impact on firm innovation. In terms of enterprise characteristics, state-owned enterprises (SOEs) are more disadvantageous than non-SOEs in terms of technological efficiency and motivation to innovate due to their strong social responsibility and the influence of the government in their decision-making, which places more emphasis on increasing output in their production operations, despite their larger volume of R\&D investment $[5,6]$. However, with the advancement of SOE reform, scholars have presented different findings. According to Xie et al. [10], government policy support and financial support have an important impact on enterprise $\mathrm{R} \& \mathrm{D}$, and SOEs are more likely to be favored by government innovation policies and resources, and SOEs show stronger innovation compared to
non-SOEs. In contrast, $\mathrm{Wu}[11]$ argues that the nature of a firm's property rights does not have a significant effect on its innovation output. In addition, firm size also has an impact on firm innovation. Large-scale enterprises are the main force of technological innovation, with strong scale effect, more strength, better risk tolerance, and more ability to carry out innovation activities, while SMEs are often constrained by their strength to carry out large-scale innovation investment, and innovation efficiency is lower [12-14]. Bound et al. [15] found that there is a " $U$ " shaped relationship between firm size and R\&D investment. By examining a large sample of firms, Zhang et al. [16] suggest that this nonlinear relationship between firm size and firm innovation is the result of the "Schumpeterian effect" and the "escape from competition effect." From the perspective of shareholding structure and corporate governance, Baysinger et al. [7, 8] argue that shareholding concentration and whether the chairman is also the general manager determine the shareholders' ability to control the direction of strategic decisions. The higher shareholding concentration enhances shareholders' supervision of managers, reduces principalagent costs, and thus promotes corporate innovation, while CEO duality phenomenon (the chairman is also the general manager) enhances the decision-making position of the general manager and weakens the board members. This is not conducive to innovative decision-making [17].

\subsection{Effectiveness of Financial Development on the Techno-} logical Innovation of Enterprises. As early as 1912, Schumpeter mentioned that financial development could enhance technological innovation and thus promote economic growth. With the continuous improvement of the financial system, financial services for the real economy continue to grow [18]. A sound financial system can help enterprises to innovate by integrating effective market information, improving the efficiency of savings-investment conversion, and diversifying and mitigating risks. First, financial development can effectively alleviate market information asymmetry. On the one hand, financial institutions can provide financial support to enterprises with innovation potential through information identification and screening of innovative enterprises, avoiding financial mismatch, and improving the efficiency of credit fund use [19]. On the other hand, a sound financial system can provide investors with more information on the current market situation and industry prospects of investment projects, reducing the cost for investors to obtain information and enhancing their willingness to invest [20]; secondly, financial development can promote the transformation of savings-investment. Financial development brings together idle social capital and transforms it into medium- and long-term credit that can be invested in production, raising investment by reducing savings in order to realize diversified financing options for enterprise $\mathrm{R} \& \mathrm{D}$ activities, so that enterprise $\mathrm{R} \& \mathrm{D}$ activities can receive more external financial support [21]; finally, financial development helps to disperse innovation risks. The financial system can combine innovation projects with different degrees of risk and distribute the risk to investors 
with higher risk tolerance, while compensating these investors with investment returns that match the investment risk, thus providing long-term and stable liquidity support for enterprise R\&D activities [22]. With the development of spatial measurement techniques, the spatial spillover properties of finance have been uncovered by scholars and its importance for corporate innovation has been further revealed. Li et al. [23] found that the scale, structure, and efficiency of financial development are all conducive to the enhancement of regional innovation output and pointed out that the dynamic flow of financial factors can deepen regional innovation output capacity by strengthening the financial aggregation effect and the spatial diffusion effect. Financial factors will flow from regions with low marginal rates of return to regions with high marginal rates of return through the spatial spillover effect, and the level of regional financial development not only has a significant role in promoting the technological innovation of enterprises in the region, but also effectively promotes the technological innovation of enterprises in the surrounding areas [24].

In general, although scholars at home and abroad have conducted a large number of academic studies on the impact of finance on enterprise innovation, and the research conclusions obtained are worthy of reference, there are still a few points that need to be further improved and supplemented: firstly, most of the existing literature has been analyzed from a macroperspective, while the specific effects of finance on enterprise innovation are relatively underemphasized by enterprises as the main subjects of market economy activities; secondly, for financial technology, as a financial resource allocation system that integrates financial innovation and technological innovation, it is necessary to subdivide the path of its effect on enterprise technological innovation, but most of the literature is limited to empirical analysis of the overall impact from different perspectives, and in-depth research on its specific path needs to be supplemented; finally, the sensitivity of enterprises with different attributes and characteristics to financial technology varies. Therefore, further tests on the driving effect of Fintech on firms' technological innovation need to be conducted in subsamples. Does the development of Fintech have a driving effect on firms' technological innovation? What is the specific mechanism of its effect? Does this effect differ across firms with different characteristics? To address the above questions, this paper empirically examines the impact effect, mechanism paths, and heterogeneity characteristics of Fintech on corporate technological innovation by taking A-share listed enterprises in Shanghai and Shenzhen markets in China from 2011-2019 as the research object to provide further refinement and supplement to the relevant research areas.

\section{Research Methodology}

\subsection{Theoretical Analysis and Research Hypothesis}

3.1.1. The Driving Effect of Fintech on Corporate Technology Innovation. Fintech has driven the further development of the financial system and is important for improving the traditional financial model. As a disruptive financial innovation, Fintech provides a solution to the problems of high information asymmetry, inaccurate risk assessment, and geographical limitations in China's traditional financial structure [25]. Fintech can effectively expand the boundaries of financial services under its huge reach effect, promote the "derealization" of the financial industry, alleviate the information asymmetry between financial institutions and enterprises, and lower the high financial service threshold of traditional financial models, thus increasing the availability of $\mathrm{R} \& \mathrm{D}$ funds and stimulating the innovation potential of enterprises [26]. At the same time, traditional financial institutions can efficiently and quickly integrate high-frequency mass data of individuals, enterprises, and industries through big data and artificial intelligence technologies and establish a relatively perfect third-party credit system to more systematically conduct accurate risk evaluation of enterprises, reducing information search costs and credit risk premiums while improving the efficiency of financial services and effectively promoting enterprise technological innovation [27-29]. The development of financial technology has also greatly enhanced the geographical penetration of financial services, extending financial services to the "long tail" of the "last mile," broadening the financing channels of enterprises, increasing the scale of enterprise financing, and thus significantly promoting enterprise technological innovation [30]. The development of Fintech has a significant role in promoting technological innovation [30]. In addition, the development of Fintech has, to a certain extent, broken the competition pattern of traditional financial institutions and intensified the competition among commercial banks and other financial institutions, which has triggered the "catfish effect," making it easier for enterprises to obtain R\&D financing and helping them to innovate [31]. From a microperspective, at the individual level, Fintechs have broken down traditional barriers to financial transactions, giving rise to financial services such as "microfinance" and "ant chanting," which have eased individual liquidity constraints and facilitated personal consumption and investment activities [32] At the enterprise level, the reshaping of payment and clearing systems has led to the rapid development of e-commerce and innovation in financial models, and more importantly, digital technology has provided enterprises with a large amount of information on application scenarios, offering more opportunities for product development and technological innovation [26]. Based on the above analysis, this paper puts forward the following hypothesis:

$\mathrm{H}_{1}$ : Fintech has a significant driving effect on enterprise technological innovation

3.1.2. Mechanisms for Fintech to Influence Corporate Technology Innovation. Innovative activities of enterprises are inseparable from sufficient financial support, and the determination of financial sources becomes the prerequisite of enterprise technological innovation. From the external point of view, the source of funds for enterprise technology innovation is mainly the financing from market financing 
agents but often faces the constraint of financing constraints; from the internal point of view, the source of funds for enterprise technology innovation is mainly the enterprise's funds from profitability. Therefore, this paper analyzes the mechanism of the role of financial technology on enterprise technology innovation with two indicators: financing constraints and profitability.

The improvement of financial technology can effectively alleviate the financing constraint of enterprises, so that enterprises can have more funds to invest in R\&D and thus promote enterprise technology innovation. Firstly, the high sunk cost, long R\&D cycle, and uncertain risk of technological innovation activities make enterprises prefer to invest in short and quick projects, thus crowding out their investment in technological $R \& D$ projects [33]; secondly, the information asymmetry, large capital demand, and uncertain return of enterprise R\&D activities make banks less willing to establish bank-enterprise relationships, forcing enterprises to face the pain of financing constraints [34]; when financing constraints are more serious, enterprises tend to cut their investment in innovation projects, which is not conducive to their technological innovation; finally, in terms of financing structure, indirect financing from banks and other financial institutions, as the main external financing channel for enterprises, high-cost single financing method reduces the possibility of enterprises' R\&D investment, and enterprises' will to innovate is depressed. The application of financial technology has alleviated this financing constraint problem of enterprises. On the one hand, Fintech not only reduces the information asymmetry between banks and enterprises, but also reduces the threshold of financial services in the financial system and alleviates the financing constraints of enterprises; on the other hand, Fintech breaks the traditional indirect financing mode inherent in enterprises and builds a diversified modern financing system with "direct financing as the main source and indirect financing as a supplement." On the other hand, Fintech breaks the traditional indirect financing mode of enterprises and builds a diversified modern financing system with "direct financing as the main and indirect financing as a supplement" [35], and the diversification of enterprise R\&D financing channels makes enterprise financing easier and effectively promotes technological innovation activities. Given the above studies, this paper argues that Fintech may promote enterprise technology innovation by alleviating enterprise financing constraints. Therefore, this paper proposes the following hypothesis:

$\mathrm{H}_{2}$ : Fintech promotes corporate technology innovation by alleviating corporate financing constraints

Fintech enhances corporate profitability through its technological advantages, allowing companies to have more funds to invest in R\&D projects and increasing the possibility of technological innovation. First, the rise of Fintech helps to improve the profitability of enterprises, requiring the demand information to be precisely positioned. Fintech can realize the connection between enterprises and C-terminal customers through big data, artificial intelligence, and other emerging technology platforms, enabling enterprises to more accurately grasp consumer preferences, demand pain points, and other information. At the same time, enterprises can segment consumer demand preferences through Fintech and adjust behavioral decisions to meet more consumers [36]. Second, operational costs are effectively reduced. With the rise of Fintech, the business operation mode and business processes have undergone fundamental changes, which greatly promote the enterprises to improve their services, quality, and efficiency by leaps and bounds [37], and should break the shackles of transaction time and geographical factors between buyers and sellers, reducing the operating costs of enterprises. Finally, the decision-making orientation is more scientific. The application of financial technology has improved the level of enterprise management decision-making and marketing, making the long-term reliance on intuition and theoretical empirical judgment give way to scientific decision-making supported by data, which guarantees the correctness and scientificity of enterprise decision-making direction [38]. In addition, since Fintech enhances the transparency of corporate accounting information, realizes real-time effective supervision of the internal capital allocation of enterprises, conducts information search for enterprises beforehand, conducts credit assessment of financing subjects during the process, and supervises their behavior afterwards, financial institutions can effectively reduce the operational risks of enterprises due to the imbalance of their internal capital allocation and the abnormal operation of external capital markets, thus leading to lower risk of corporate innovation [39]. Profitability, as a prerequisite for sustainable corporate development, also provides financial security for corporate $\mathrm{R} \& \mathrm{D}$ and enhances corporate willingness for technological innovation, which also illustrates the contribution of profitability to corporate technological innovation. Based on the above analysis, this paper examines the identification of mechanisms by which Fintech affects corporate technological innovation in terms of profitability, where profitability is measured by operating profit. This paper proposes the following hypothesis:

$\mathrm{H}_{3}$ : Fintech can promote corporate technological innovation by improving corporate profitability

\subsection{Data Sources and Selection of Variables}

3.2.1. Data Sources and Data Processing. In this paper, the A-share listed enterprises in Shanghai and Shenzhen from 2011-2019 are used as research objects, the patent data used are from manual processing, the data of Fintech are from the Digital Inclusive Finance Index compiled by the Internet Finance Research Center of Peking University, and the financial data, corporate characteristics, and R\&D information of enterprises are from the CHOICE database. To make the sample data more representative, the data are processed as follows: (i) companies that have IPOs during the sample period are excluded; (ii) companies with incomplete financial data and corporate governance data are excluded; (iii) in order to avoid the influence of outliers, the sample with no missing data for at least 5 consecutive years is 
retained; (iv) in order to eliminate the influence of extreme values on the study, the $1 \%$ tailing process was performed for the relevant indicators. After the above processing, 25,955 observation samples were finally obtained.

\subsubsection{Selection of Variables}

(1) Explanatory Variables. Enterprise Technology Innovation: Previously, scholars mainly used innovation input and innovation output to measure the level of enterprise technology innovation. Regarding innovation input, most of them take R\&D input as an important indicator of enterprise technology innovation input. Regarding innovation output, it is the number of patents applied and the number of new products developed as the measure of enterprise technology innovation. Yang et al. [40] measured the three indicators of the presence or absence of enterprise innovation, the presence or absence of enterprise patent applications, and the presence or absence of enterprise innovation activities to measure enterprise technology innovation. However, most technology-based enterprises are more or less innovative, and this measurement method is relatively crude. In this paper, we adopt the number of patent applications to measure the level of enterprise technological innovation, which is reflected as the result of R\&D investment and better reflects the transformation efficiency of enterprise technology investment. Patent applications are divided into the number of independent invention applications, the number of independent practical invention applications, and the number of independent appearance patent applications. Since the number of independent appearance patent applications is easier to obtain and less representative of enterprise technological innovation, this paper uses the number of independent invention patent applications and independent utility model patent applications as proxy variables for enterprise technological innovation activities.

(2) Core Explanatory Variables. Fintech: Drawing on the study of Guo et al. [41], this paper uses the provincial-level China Digital Financial Inclusion Index compiled by the Digital Finance Research Center of Peking University as a proxy variable for Fintech. The index is based on Ant Financial Services transaction account data and provides a more comprehensive picture of the level of digital financial development through three dimensions: 1 . breadth of digital financial coverage (number of Alipay accounts per 10,000 people, the proportion of Alipay card-tied users, average number of bank cards tied to each Alipay account, etc.); 2 . depth of digital financial usage (number of payment strokes per capita, payment amount per capita, number of Alipay users per 10,000 buying balance, etc.); 3 . the degree of digitization (the proportion of mobile payment amount, the proportion of Taobao payment amount, the average loan interest rate of small and micro operators, etc.). In the core empirical part of this paper, the Total Digital Inclusive Finance Index is used as a proxy variable for Fintech, and in the robustness test, two-dimensional indicators of the breadth of digital inclusive finance coverage as well as the depth of use are used for measuring.
(3) Control Variable. In order to avoid the influence of other noncore variables as much as possible, this paper includes several control variables in the regression model. These include year-over-year growth rate of gross operating income, gearing ratio, capital intensity, return on net assets, the shareholding ratio of major shareholders, liquidity ratio, quick ratio, working capital to total assets ratio, two jobs concurrently, duration, whether it is a state-owned enterprise, total equity, and GDP.

3.2.3. Model Setting. To test the impact of Fintech on corporate technology innovation, the following model is constructed in this paper:

$$
\mathrm{PAT}_{i, t}=\beta_{0}+\beta_{1} \mathrm{DIF}_{m, t}+\beta_{2}^{\prime} \operatorname{Control}_{i, t}+\delta_{i}+\theta_{t}+\varepsilon_{i, t} .
$$

Among them, the explanatory variable $\mathrm{PAT}_{i, t}$ is the innovation output of company $i$ in year $t$, measured by the number of corporate patent applications; the explanatory variable DIF $m, t$ indicates the level of Fintech development in company $i$ 's province $m$ in year $t$, measured by the Digital Inclusive Finance Index at the provincial level. Control $_{i, t}$ denotes control variables, including the year-on-year growth rate of gross operating income, debt-to-asset ratio, capital intensity, return on net assets, the shareholding ratio of major shareholders, liquidity ratio, quick ratio, working capital to total assets ratio, CEO duality phenomenon, duration of existence, dummy (SOE or not), total equity, and GDP. $\delta_{i}$ denotes individual firm fixed effects, and since regional fixed effects are absorbed by individual firm fixed effects, essentially this paper also controls for regional fixed effects. $\theta_{t}$ denotes time fixed effects to control for time-varying unobservables, and the subscript $t$ denotes year. $\varepsilon_{i, t}$ denotes the random error term. The coefficient $\beta_{1}$ of the core explanatory variable $\mathrm{PAT}_{i, t}$ indicates the impact of Fintech development on firm innovation, which is expected to be significantly positive according to the research hypothesis of this paper.

\section{Results and Analysis}

4.1. Baseline Regression Results. Table 1 shows the results of the baseline regression of Fintech on enterprise technology innovation. In order to control the number of patent applications at the enterprise level with disturbing factors, this study controlled for individual and time fixed effects. As shown in columns (1)-(3) of Table 1, the regression coefficients of the total index of Fintech (such as, the breadth of Fintech coverage and the depth of Fintech usage on enterprise technology innovation) are positive and significant, indicating that Fintech has a significant positive effect on enterprise technology innovation. Columns (4)-(6) in Table 1 show that, with the number of independent utility models as a proxy variable for enterprise technology innovation, the regression coefficients of the total Fintech index, the breadth of Fintech coverage, and the depth of Fintech usage on enterprise technology innovation are all significantly positive. This paper concludes that Fintech does have a significant driving effect on enterprise technology innovation, as evidenced by $\mathrm{H}_{1}$. 
TABLE 1: Baseline regression results.

\begin{tabular}{|c|c|c|c|c|c|c|}
\hline & (1) & $(2)$ & (3) & (4) & (5) & $(6)$ \\
\hline & \multicolumn{3}{|c|}{ Number of patent applications } & \multicolumn{3}{|c|}{$\begin{array}{c}\text { Number of utility model patent } \\
\text { applications }\end{array}$} \\
\hline Total Digital Inclusive Finance Index & $\begin{array}{c}0.113^{* * *} \\
(3.09)\end{array}$ & & & $\begin{array}{c}0.212^{* * *} \\
(3.34)\end{array}$ & & \\
\hline Digital inclusive finance coverage breadth index & & $\begin{array}{c}0.136^{* *} \\
(2.26)\end{array}$ & & & $\begin{array}{c}0.250^{* *} \\
(2.40)\end{array}$ & \\
\hline Digital inclusive finance usage depth index & & & $\begin{array}{c}0.057^{* * *} \\
(2.97)\end{array}$ & & & $\begin{array}{c}0.084^{* *} \\
(2.50)\end{array}$ \\
\hline _cons & $\begin{array}{r}-7.415^{*} \\
(-1.79)\end{array}$ & $\begin{array}{c}-8.694^{*} \\
(-1.79)\end{array}$ & $\begin{array}{l}-5.153 \\
(-1.33)\end{array}$ & $\begin{array}{c}-18.783^{* * *} \\
(-2.62)\end{array}$ & $\begin{array}{c}-20.939^{* *} \\
(-2.49)\end{array}$ & $\begin{array}{r}-13.049^{*} \\
(-1.94)\end{array}$ \\
\hline Control variable & Yes & Yes & Yes & Yes & Yes & Yes \\
\hline Individual effect & Yes & Yes & Yes & Yes & Yes & Yes \\
\hline Time effects & Yes & Yes & Yes & Yes & Yes & Yes \\
\hline$N$ & 24711 & 24711 & 24711 & 24711 & 24711 & 24711 \\
\hline$R^{2}$ & 0.019 & 0.019 & 0.019 & 0.029 & 0.029 & 0.029 \\
\hline
\end{tabular}

Note: the marginal effects of each explanatory variable are reported in the table. The $t$-values are in parentheses. ${ }^{* * *},{ }^{* *}$, and ${ }^{*}$ indicate significance at the $1 \%$, $5 \%$, and $10 \%$ levels, respectively. Subsequent tables are consistent with this table.

\subsection{Robustness Analysis}

4.2.1. Endogenous Processing. Given that the potential influence of endogeneity may cause bias in the estimation results, this paper uses the national average level of Fintech development rather than the province average as the instrumental variable. The enterprise technology innovation does not have a direct influence on the average development level of financial technology in foreign provinces, which satisfies the exogenous condition, while the overall development trend of domestic financial technology is consistent. Thus, the degree of financial technology development is similar, and the development level of financial technology in this province has strong synergy with the average development level of financial technology in foreign provinces, which satisfies the correlation condition and conforms to the selection principle of exogeneity and correlation of instrumental variables. The instrumental variable method is used for estimation, and Table 2 shows the regression results of the impact of Fintech on enterprise technological innovation. As far as the experimental results are concerned, in terms of the endogeneity test, Fintech significantly passes the Wald test at the $1 \%$ level for both the number of invention patents and the number of utility model patents, indicating the existence of endogeneity. And the F-value of the instrumental variable at one stage is much greater than 10 , which excludes the problem of weak instrumental variables, which indicates that it is appropriate to adopt the average level of financial technology development in foreign provinces as the instrumental variable. From the regression results in Table 2, both the number of invention patent applications and the number of utility model patent applications, after correcting for the endogeneity bias, still have a significant promoting effect of Fintech, indicating that Fintech does have a significant driving effect on enterprise technology innovation, which is consistent with the above research findings and the experimental results are robust.
4.2.2. Replacement Models. In the previous benchmark regressions, we control for individual and time fixed effects separately. Among them, individual fixed effects aim to capture the characteristics of firm technological innovation that do not change over time, and time fixed is to control for the characteristics of firm technological innovation that change over time in each year to mitigate the effects of firm characteristics and macroeconomic factors on the estimation results. To ensure that the estimation results do not vary with changes in the model, this paper adopts the OLS estimation method for further robustness checks. At the same time, because there are some differences in the level of enterprise technology innovation development among industries and provinces, this paper adds industry fixed effects and province fixed effects factors to the regression for robustness testing, and the results are shown in Table 3. The results show that, after changing the model estimation method and controlling for industry fixed effects and province fixed effects, the effects of the total index of financial technology, the breadth of coverage, and the depth of use on enterprise technology innovation are all significantly positive at the $1 \%$ level, indicating that the promotion effect of financial technology on enterprise technology innovation is still significant and the research findings still hold.

4.2.3. Substitution of Variables. In order to avoid bias in the regression results due to the single selection of variables, the robustness is tested by changing the caliber of the proxy variables. The three dimensional indicators of total Fintech index, breadth of Fintech coverage, and depth of Fintech usage are adopted to portray Fintech. And the number of invention patents and the number of utility model patents are taken as the proxy variables of enterprise technology innovation, respectively. As shown in the results of Table 4, the results are still robust after changing the caliber of proxy variables. 
TABLE 2: Instrumental variable method test.

\begin{tabular}{|c|c|c|}
\hline & $\begin{array}{c}(1) \\
\text { Number of patent applications }\end{array}$ & $\begin{array}{c}(2) \\
\text { Number of utility model patent applications }\end{array}$ \\
\hline Total Digital Inclusive Finance Index & $\begin{array}{c}0.654^{* * *} \\
(6.43)\end{array}$ & $\begin{array}{c}0.876^{* * *} \\
(4.80)\end{array}$ \\
\hline Control variable & Yes & Yes \\
\hline Time effects & Yes & Yes \\
\hline Individual effect & Yes & Yes \\
\hline$N$ & 24583 & 24583 \\
\hline$R^{2}$ & 0.009 & 0.024 \\
\hline
\end{tabular}

TABLE 3: Least squares method for controlling provinces and industries.

\begin{tabular}{|c|c|c|c|c|c|c|}
\hline & (1) & (2) & (3) & \multirow{2}{*}{\multicolumn{3}{|c|}{$\begin{array}{l}\text { (4) } \\
\text { Number of utility model patent } \\
\text { applications }\end{array}$}} \\
\hline & \multicolumn{3}{|c|}{ Number of patent applications } & & & \\
\hline Total Digital Inclusive Finance Index & $\begin{array}{c}0.038^{* * * *} \\
(5.24)\end{array}$ & & & $\begin{array}{c}0.070^{* * * *} \\
(6.36)\end{array}$ & & \\
\hline Digital inclusive finance coverage breadth index & & $\begin{array}{c}0.040^{* * * *} \\
(5.14)\end{array}$ & & & $\begin{array}{c}0.074^{* * *} \\
(6.29)\end{array}$ & \\
\hline Digital inclusive finance usage depth index & & & $\begin{array}{c}0.034^{* * *} \\
(4.91)\end{array}$ & & & $\begin{array}{c}0.058^{* * *} \\
(5.52)\end{array}$ \\
\hline -cons & $\begin{array}{c}-40.054^{* * *} \\
(-8.32)\end{array}$ & $\begin{array}{c}-39.804^{* * *} \\
(-8.29)\end{array}$ & $\begin{array}{c}-40.068^{* * *} \\
(-8.20)\end{array}$ & $\begin{array}{c}-78.612^{* * *} \\
(-9.69)\end{array}$ & $\begin{array}{c}-78.140^{* * *} \\
(-9.66)\end{array}$ & $\begin{array}{c}-77.979^{* * *} \\
(-9.54)\end{array}$ \\
\hline Control variable & Yes & Yes & Yes & Yes & Yes & Yes \\
\hline Industry effect & Yes & Yes & Yes & Yes & Yes & Yes \\
\hline Provincial effect & Yes & Yes & Yes & Yes & Yes & Yes \\
\hline$N$ & 24711 & 24711 & 24711 & 24711 & 24711 & 24711 \\
\hline$R^{2}$ & 0.089 & 0.089 & 0.089 & 0.158 & 0.158 & 0.158 \\
\hline
\end{tabular}

Table 4: Descriptive statistics.

\begin{tabular}{|c|c|c|c|c|c|}
\hline Variable name & Observed value & Mean value & $\begin{array}{l}\text { Standard } \\
\text { deviation }\end{array}$ & Minimum value & Maximum value \\
\hline Number of invention patents & 25955 & 9.008939 & 62.780 & 0 & 3096 \\
\hline Number of utility model patents & 25955 & 22.36113 & 99.148 & 0 & 3823 \\
\hline Total Digital Inclusive Finance Index & 25955 & 238.0898 & 94.316 & 16.22 & 410.2814 \\
\hline Digital inclusive finance usage depth index & 25955 & 241.3122 & 97.136 & 6.76 & 439.9118 \\
\hline Digital inclusive finance coverage breadth index & 25955 & 219.0716 & 91.578 & 1.96 & 384.6559 \\
\hline Year-on-year growth rate of total operating income & 25938 & 14.87617 & 34.681 & -59.15492 & 192.6067 \\
\hline Assets and liabilities ratio & 25955 & 43.33013 & 22.034 & 5.07504 & 94.86151 \\
\hline Capital intensity & 24763 & 47.18975 & 22.186 & 3.732843 & 91.3196 \\
\hline Return on net assets & 25787 & 6.453716 & 14.127 & -74.84134 & 38.02006 \\
\hline Shareholding ratio of major shareholders & 25949 & 34.43763 & 14.887 & 8.54 & 74.3 \\
\hline Liquidity ratio & 25459 & 2.546113 & 2.739 & 0.2727728 & 17.75019 \\
\hline Quick ratio & 25459 & 2.035293 & 2.511 & 0.1619173 & 16.10343 \\
\hline Working capital to total assets ratio & 25459 & 22.97224 & 26.074 & -44.68603 & 79.96218 \\
\hline CEO duality phenomenon & 25955 & 0.2542863 & 0.435 & 0 & 1 \\
\hline Duration of existence & 25955 & 21.52448 & 5.225 & 10 & 38 \\
\hline Whether it is a state-owned enterprise & 25955 & 0.365209 & 0.481 & 0 & 1 \\
\hline Total equity & 25955 & $1.67 e+09$ & $2.97 e+09$ & $1.12 e+08$ & $2.11 e+10$ \\
\hline GDP & 25955 & 425.9729 & 270.468 & 6.115 & 1079.869 \\
\hline
\end{tabular}

\section{Analysis of Impact Mechanisms}

The above section has verified the impact of Fintech on corporate technology innovation. However, only the overall driving effect has been examined, and the specific mechanism "black box" has not been opened. Further empirical testing of the mechanism is necessary.

Combining the two possible impact paths proposed in the previous section: financing constraints and profitability, this paper will test the mechanism of these two paths 
separately and adopt the stepwise regression method to test the mechanism, drawing on the method of Wen and Ye [42], with the following steps:

$$
\begin{aligned}
\operatorname{PAT}_{i, t} & =\beta_{0}+\beta_{1} \mathrm{DIF}_{m, t}+\beta_{2}^{\prime} \operatorname{Control}_{i, t}+\delta_{i}+\theta_{t}+\varepsilon_{i, t}, \\
M_{i, t} & =\alpha_{0}+\alpha_{1} \mathrm{DIF}_{m, t}+\alpha_{2}^{\prime} \operatorname{Control}_{i, t}+\delta_{i}+\theta_{t}+\varepsilon_{i, t}, \\
\operatorname{PAT}_{i, t} & =\varphi_{0}+\varphi_{1} \mathrm{DIF}_{m, t}+\varphi_{2} M_{i, t}+\varphi_{2}^{\prime} \operatorname{Control}_{i, t}+\delta_{i}+\theta_{t}+\varepsilon_{i, t},
\end{aligned}
$$

where $M$ is the mediating variable, the total effect of the impact of Fintech on firms' technological innovation is $\beta_{1}$, the direct effect is $\varphi_{1}$, and the indirect effect of the variable $M$ is $\varphi_{2}$.

5.1. Financing Constraint Mechanism. The financing constraint mechanism refers to the fact that Fintech promotes enterprise technology innovation by alleviating enterprise financing constraints. In this paper, we use the number of invention patents as a proxy variable for enterprise technological innovation to test the mechanism of "Fintech-financing constraint-enterprise technological innovation." The SA index is calculated as SA $=-0.737$ size +0.043 size $^{2}-0.04$ age, where size is the total assets of the firm in millions of dollars and age is the number of years the firm has been established. The resulting index is calculated as a negative value, and the smaller the value, the more serious the financing constraints faced, and vice versa. The results are shown in Table 5. The coefficient of the level of financial technology development is significantly positive in column (2), which means that the development of financial technology helps to alleviate the financing constraint of enterprises; meanwhile, the coefficient of the financing constraint of enterprises in column (3) is significantly positive, which means that the alleviation of the financing constraint of enterprises helps to promote the technological innovation of enterprises. The above results show that the intermediation effect holds and the financing constraint is partially intermediated, and hypothesis $\mathrm{H}_{2}$ is proved.

5.2. Profitability Mechanism. Profitability mechanism means that Fintech can promote enterprise technology innovation by improving enterprise profitability. In this paper, we use operating profit as the proxy variable of enterprise profitability to test the "Fintech-operating profit-enterprise technology innovation" mechanism. The results are shown in Table 6. The coefficient of enterprise profitability in column (2) is 1.773 and is significantly positive at the $5 \%$ level, indicating that there is a significant promotion effect of Fintech on enterprise profitability, which also means that the market-oriented nature of Fintech makes enterprise operating profit increase significantly. In the regression in column (3), the coefficient of profitability is 0.005 and significantly positive, which indicates that the enhancement of corporate profitability is conducive to the improvement of corporate technological innovation. In addition, controlling for firm profitability, the effect of Fintech on firm technological innovation is significant and the mechanism holds and hypothesis $\mathrm{H}_{3}$ is confirmed.

\section{Heterogeneity Analysis}

The previous paper examined the impact of Fintech and corporate technology innovation and the mechanism of action, but does the impact of Fintech on corporate innovation differ across firms with different characteristics? In this paper, we examine the heterogeneity of three major characteristics: the duration of the firm, the property rights attributes, and whether the firm is backdoor listing.

6.1. Heterogeneity Based on the Duration of the Business. Does the driving effect of Fintech on corporate innovation differ between new and old firms? The results are shown in Table 7. Columns (1) and (2) take the mean value of the years of listing as the threshold, and the sample firms are divided into those with longer listing time and those with shorter listing time. The experimental results show that the technological innovation of Fintech is more significant for shorter-listed firms, with a regression coefficient of 0.222 and passing the $1 \%$ significance level, while it is not significant for longer-listed firms. This implies that Fintech is more effective in promoting technological innovation in new firms than in old firms. Possible reasons for this are the high competitive pressure of firms in the growth period, the lack of collateral assets, and the fact that the "bond" with banks and other financial institutions has not yet been established, which makes it difficult for banks to grasp the operational status and financial information of new firms, thus the general phenomenon of "lending hesitation" [43]. With the lack of integration of resource elements and stable customer relationships in the formative years of enterprises, the high degree of information asymmetry, and the difficulty in establishing the legitimization of a large number of stakeholders, including investors [44, 45], Fintech, with its technological advantages, ushers in new opportunities for the development of new enterprises, and by increasing the transparency of information between banks and enterprises, it reduces information asymmetry as well as agency costs, enhances the willingness of banks and other financial institutions to invest and lend, broadens the financing channels of new enterprises, and helps the implementation of technological innovation activities of enterprises.

6.2. Heterogeneity Based on the Nature of Property Rights. The controversy about the nature of property rights and the effectiveness of innovation has been longstanding. At a time when the financial industry is changing rapidly under the leadership of financial technology, is there any difference in the impact of financial technology on enterprise technological innovation among enterprises with different property rights? The results in columns (3) and (4) of Table 7 show that, for state-owned enterprises, the coefficient of Fintech is 0.366 and positive at $1 \%$ significance level, indicating that Fintech has a significant effect on driving their technological innovation activities. For non-SOEs, the effect of Fintech on technological innovation is not significant. The possible reasons should be the following points: On the one hand, the innovation efficiency of SOEs in China is generally lower compared to non- 
TABLE 5: Intermediary mechanisms, financing constraints.

\begin{tabular}{|c|c|c|c|}
\hline & $\begin{array}{c}\text { (1) } \\
\text { Number of patent applications }\end{array}$ & $\begin{array}{c}(2) \\
\text { SA index }\end{array}$ & $\begin{array}{c}(3) \\
\text { Number of patent applications }\end{array}$ \\
\hline Total Digital Inclusive Finance Index & $\begin{array}{c}0.113^{* * *} \\
(3.09)\end{array}$ & $\begin{array}{c}0.000^{* * *} \\
(3.06)\end{array}$ & $\begin{array}{c}0.098^{* * *} \\
(2.70)\end{array}$ \\
\hline SA index & & & $\begin{array}{c}78.527^{* * *} \\
(20.11)\end{array}$ \\
\hline _cons & $\begin{array}{c}-7.415^{*} \\
(-1.79)\end{array}$ & $\begin{array}{c}-4.105^{* * *} \\
(-567.94)\end{array}$ & $\begin{array}{c}314.906^{* * *} \\
(19.04)\end{array}$ \\
\hline Control variable & Yes & Yes & Yes \\
\hline Time effects & Yes & Yes & Yes \\
\hline Individual effect & Yes & Yes & Yes \\
\hline$N$ & 24711 & 24703 & 24703 \\
\hline$R^{2}$ & 0.019 & 0.088 & 0.037 \\
\hline
\end{tabular}

TABLE 6: Intermediary mechanisms, profitability.

\begin{tabular}{|c|c|c|c|}
\hline & $\begin{array}{c}\text { (1) } \\
\text { Number of patent applications }\end{array}$ & $\begin{array}{c}(2) \\
\text { Profitability }\end{array}$ & $\begin{array}{c}(3) \\
\text { Number of patent applications }\end{array}$ \\
\hline Total Digital Inclusive Finance Index & $\begin{array}{l}0.113^{* * *} \\
(3.09)\end{array}$ & $\begin{array}{c}1.773^{* *} \\
(1.99)\end{array}$ & $\begin{array}{l}0.104^{*} \\
(1.65)\end{array}$ \\
\hline Profitability & & & $\begin{array}{c}0.005^{* *} \\
(2.23)\end{array}$ \\
\hline _cons & $\begin{array}{r}-7.415^{*} \\
(-1.79)\end{array}$ & $\begin{array}{c}-100.249 \\
(-0.99)\end{array}$ & $\begin{array}{l}-6.898 \\
(-1.29)\end{array}$ \\
\hline Control variable & Yes & Yes & Yes \\
\hline Time effects & Yes & Yes & Yes \\
\hline Individual effect & Yes & Yes & Yes \\
\hline$N$ & 24711 & 24711 & 24711 \\
\hline$R^{2}$ & 0.019 & 0.169 & 0.034 \\
\hline
\end{tabular}

TABLE 7: Heterogeneity analysis.

\begin{tabular}{|c|c|c|c|c|c|c|}
\hline & $\begin{array}{c}(1) \\
\text { Longer life span }\end{array}$ & $\begin{array}{c}(2) \\
\text { Short life span }\end{array}$ & $\begin{array}{c}\text { (3) } \\
\text { State-owned }\end{array}$ & $\begin{array}{c}(4) \\
\text { Non-state-owned }\end{array}$ & $\begin{array}{c}\text { (5) } \\
\text { Backdoor listing }\end{array}$ & $\begin{array}{l}(6) \\
\mathrm{IPO}\end{array}$ \\
\hline Total Digital Inclusive Finance Index & $\begin{array}{l}0.050 \\
(0.87)\end{array}$ & $\begin{array}{c}0.222^{* * * *} \\
(5.54)\end{array}$ & $\begin{array}{c}0.366^{* * *} \\
(5.14)\end{array}$ & $\begin{array}{l}-0.038 \\
(-1.13)\end{array}$ & $\begin{array}{c}0.099^{*} \\
(1.68)\end{array}$ & $\begin{array}{c}0.117^{* * *} \\
(3.13)\end{array}$ \\
\hline _cons & $\begin{array}{l}-1.515 \\
(-0.23)\end{array}$ & $\begin{array}{c}-12.721^{* * *} \\
(-3.00)\end{array}$ & $\begin{array}{l}4.912 \\
(0.46)\end{array}$ & $\begin{array}{l}2.623 \\
(0.78)\end{array}$ & $\begin{array}{l}-0.822 \\
(-0.15)\end{array}$ & $\begin{array}{r}-7.753^{*} \\
(-1.87)\end{array}$ \\
\hline Control variable & Yes & Yes & Yes & Yes & Yes & Yes \\
\hline Time effects & Yes & Yes & Yes & Yes & Yes & Yes \\
\hline Individual effect & Yes & Yes & Yes & Yes & Yes & Yes \\
\hline$N$ & 11678 & 13602 & 9020 & 16260 & 1140 & 24140 \\
\hline$R^{2}$ & 0.011 & 0.037 & 0.028 & 0.014 & 0.077 & 0.019 \\
\hline
\end{tabular}

SOEs [46]. On the other hand, the "high quality and efficiency" of SOE innovation resources in China puts them in a more favorable external environment for innovation, and at the same time, SOE executives need to face the performance assessment of SASAC, so SOEs pay more attention to improve outputs of R\&D investment and innovation [47]. The support of financial technology undoubtedly brings innovation opportunities to SOEs, but non-SOEs have lower risk tolerance, lack of human capital required for R\&D, and generally lower requirements for innovation, so even if there are innovation opportunities, it is difficult to fully grasp them; thus the driving effect of Fintech development on SOEs' technological innovation is more obvious.
6.3. Heterogeneity Based on Backdoor Listing. Backdoor listing and IPO are the main ways for enterprises to go public. Backdoor listing is favored by many companies mainly because of the lower threshold and more efficiency compared to IPO listing. So is there a significant difference between IPO firms and backdoor-listed firms in terms of the impact of Fintech on firms' technological innovation? In columns (5) and (6) of Table 7, heterogeneity is tested by grouping the study samples by whether they are backdoor or not. The results show that the regression coefficients of Fintech on technological innovation of nonbackdoor firms are significant and larger than those of backdoor firms. The possible reason is that backdoor listing is essentially a 
corporate restructuring act, and compared with IPO firms, backdoor-listed firms inevitably face the challenge of resource integration. Compared with IPO firms, it is relatively difficult for backdoor firms to formulate innovation strategies and allocate related resources, so their corporate innovation is relatively less effective in being promoted by financial technology.

\section{Research Findings and Policy Recommendations}

This paper empirically examines the impact between Fintech and enterprise technological innovation using data from A-share listed enterprises in China's Shanghai and Shenzhen markets between 2011 and 2019. The findings confirm the mechanism of Fintech's effect on enterprise technological innovation and embedding enterprise heterogeneity to test the effect of Fintech on technological innovation of enterprises with different characteristics. The empirical results show that: firstly, the positive effect of Fintech on corporate technological innovation is significant; secondly, Fintech can contribute to corporate technological innovation through two transmission paths: alleviating corporate financing constraints and enhancing profitability; thirdly, further subsample studies show that the effect of Fintech in driving technological innovation among different firms exhibits significant heterogeneity: (1) compared to older firms, Fintech has a more significant effect on the technological innovation activities of new firms with a shorter duration; (2) Fintech has a positive effect on the technological innovation of state-owned enterprises but is not sensitive to the technological innovation of non-stateowned enterprises; (3) Fintech is more conducive to the technological innovation of nonbackdoor enterprises than backdoor enterprises.

Based on the above analysis, this paper puts forward the following policy implications:

Firstly, active policy support should be given to Fintech guided by emerging technologies such as artificial intelligence. The development of high-end technologies such as artificial intelligence and big data should be actively promoted to help the digital transformation of the financial industry, to guard the bottom line of not occurring systemic financial risks as the premise, to give enough space for the integration of finance and technology pilot tolerance, and to deepen the reform of the financial system.

Secondly, promote the deep integration of financial technology and real enterprises. On the one hand, in the face of new opportunities for technological development, the all-round integration of financial institutions and financial technology should be strengthened to help financial services sink accurately into the real industry and reduce the cost of financing for enterprises. On the other hand, real enterprises should be encouraged to actively introduce new technological means to continuously improve their operation models, marketing thinking, and strategic decision-making and improve their profitability, so as to lay a solid foundation for financial technologyenabled enterprise innovation.

Finally, a corresponding policy incentive system should be formulated according to the different attributes of enterprises. In terms of the duration of the enterprise, Fintech should increase its efforts to identify new entrants and encourage financial institutions to provide financial support for the research and development of new enterprises, so as to stimulate the innovation potential of new enterprises. In terms of the nature of property rights, Fintech should strengthen the depth of its services to state-owned enterprises, actively respond to the "mixed ownership reform" with state-owned participation, and encourage state-owned enterprises to implement an employee shareholding system that binds the interests of employees to those of the enterprise, so as to stimulate the enthusiasm of employees and the innovation potential of the enterprise. In addition, the financial market should be further developed to reduce the barriers to listing for quality enterprises and to avoid the impact of backdoor listings, so that they can focus more on grasping the opportunities brought by technological innovation and improving their independent innovation capacity.

\section{Limitations and Prospects}

The limitations of this paper are two: (i) the research objects selected in this paper are A-share listed enterprises in Shanghai and Shenzhen, which include various industries; although the availability of data and the diversity of data sources are ensured, the listing needs to meet the listing standards, which weakens the representativeness of the sample selection; (ii) this paper uses the Peking University Digital Inclusive Finance Index, a multidimensional index system, as a proxy variable for Fintech, where digital inclusive finance aims at the deep integration of inclusive finance and Fintech, blending inclusive characteristics, while Fintech focuses on the coupling of finance and technology, so there is a certain representativeness bias in adopting the Digital Inclusive Finance Index to measure the level of Fintech development.

Overall, China's Fintech development has made great progress, but its application is still in its infancy, and the development of new finance is still emerging. Focusing Fintech on the application of new technology research and development to financial innovation, algorithmic trading, and artificial intelligence through machine learning and deep learning has become a major trend in financial innovation. With the rapid development of new generation information technology, new technologies such as $5 \mathrm{G}$ and IoT have completely changed the original business model and management framework. 5 G's high speed, low power consumption, and low latency characteristics have broken through the traditional business competition and brought the market space for industrial automation, driverless, and many other fields, which was not possible with $3 \mathrm{G}$ or $4 \mathrm{G}$ in the past. In the context of national promotion of $5 \mathrm{G}$ popularity, those backward enterprises that cannot catch the 
tail of innovation will often face elimination, coupled with the internationalization process, the domestic competition pattern intensified, "internal volume" to stimulate the enthusiasm of enterprise innovation, external innovation wave, the combination of the market environment, and the needs of enterprises themselves to meet the innovation 2.0, the coming of the era of innovation.

\section{Data Availability}

The data used to support the findings of this study are included in the article. The sample is available from the corresponding author upon request.

\section{Conflicts of Interest}

The authors have no relevant financial or nonfinancial interests to disclose.

\section{Acknowledgments}

This study was supported by the Natural Science Foundation of Shandong Province, China (Grant no. ZR2021MG028).

\section{References}

[1] W. J. Li and M. N. Zheng, "Is it substantive innovation or strategic innovation? - impact of macroeconomic policies on micro-enterprises' innovation," Economic Research Journal, vol. 51, no. 4, pp. 60-73, 2016.

[2] M. M. Li, H. J. Xiao, and J. X. Fu, "Financial policy, enterprises' $\mathrm{R} \& \mathrm{D}$ expenditure and technological innovation capabilities empirical study from the listed companies in chinas strategic emerging industries," Management Review, vol. 26, no. 8, pp. 135-144, 2014.

[3] X. X. Xu, W. L. Li, and W. L. Lee, "Confucian tradition and corporate innovation: the power of culture," Journal of Financial Research, no. 9, pp. 112-130, 2019.

[4] J. G. Yuan, C. Cheng, and Q. S. Hou, "Environment uncertainty and firm technological innovation:evidence from Chinese listed firms," Management Review, vol. 27, no. 10, pp. 60-69, 2015.

[5] Y. Yao and Q. Zhang, "An analysis of technological efficiency of Chinese industrial firm," Economic Research Journal, no. 10, pp. 13-19, 2001.

[6] A. Zhang, Y. Zhang, and R. Zhao, "A study of the R\&D efficiency and productivity of Chinese firms," Journal of Comparative Economics, vol. 31, no. 3, pp. 444-464, 2003.

[7] B. D. Baysinger, R. D. Kosnik, and T. A. Turk, "Effects of board and ownership structure on corporate R\&d strategy," Academy of Management Journal, vol. 34, no. 1, pp. 205-214, 1991.

[8] J. Francis and A. Smith, "Agency costs and innovation some empirical evidence," Journal of Accounting and Economics, vol. 19, no. 2-3, pp. 383-409, 1995.

[9] Y. Chen, E. J. Podolski, and M. Veeraraghavan, "National culture and corporate innovation," Pacific-Basin Finance Journal, vol. 43, pp. 173-187, 2017.

[10] W. M. Xie, Q. Q. Tang, and S. S. Lu, "Government R\&D funding, firm $\mathrm{R} \& \mathrm{D}$ expenditures, and independent innovation: empirical evidence from Chinese listed firms," Journal of Financial Research, no. 6, pp. 86-99, 2009.
[11] Y. B. Wu, "R\&D and productivity: an empirical study on Chinese manufacturing industry," Economic Research Journal, no. 11, pp. 60-71, 2006.

[12] J. A. Schumpeter, Capitalism, Socialism, and Democracy, Routledge, London, UK, 2010.

[13] F. M. Fisher and P. Temin, "Returns to scale in research and development: what does the schumpeterian hypothesis imply?" Journal of Political Economy, vol. 81, no. 1, pp. 56-70, 1973.

[14] I. Booyens, "Are small, medium- and micro-sized enterprises engines of innovation? The reality in South Africa," Science and Public Policy, vol. 38, no. 1, pp. 67-78, 2011.

[15] J. Bound, C. Cummins, Z. Griliches, B. H. Hall, and A. Jaffe, Who Does ReD and Who Patents?, University of Chicago Press, Chicago, IL, USA, 2007.

[16] J. Zhang, W. P. Zheng, and F. X. Zhai, "How does competition affect innovation:evidence from China," China Industrial Economics, vol. 11, pp. 56-68, 2014.

[17] S. Finkelstein and R. A. D’Aveni, "CEO duality as a doubleedged sword: how boards of directors balance entrenchment avoidance and unity of command," Academy of Management Journal, vol. 37, no. 5, pp. 1079-1108, 1994.

[18] L. N. Zhang and H. X. Qian, "Dual-effect mechanism of regional financial development in technological innovation," Financial Economics Research, vol. 35, no. 1, pp. 104-116, 2020.

[19] X. Yi and F. L. Liu, "Financial development, technological innovation and industrial structural transformation - a framework for analysis of multisectoral endogenous growth theory," Management World, vol. 265, no. 10, pp. 24-39, 2015.

[20] T. T. Huang and B. Gao, "Financial development, financing constraints and firm innovation," Modern Economic Research, vol. 459, no. 3, pp. 22-32, 2020.

[21] R. H. Chowdhury and M. Maung, "Financial market development and the effectiveness of R\&D investment: evidence from developed and emerging countries," Research in International Business and Finance, vol. 26, no. 2, pp. 258-272, 2012.

[22] J. Du and S. Y. Liu, "Economic policy uncertainty, financial development and technological innovation," Inquiry into Economic Issues, vol. 461, no. 12, pp. 32-42, 2020.

[23] X. L. Li, G. H. Ran, and W. Zheng, "Financial development, spatial correlation and regional innovation output," $R$ \& $D$ Management, vol. 29, no. 1, pp. 55-64, 2017.

[24] S. Q. Wang and J. S. Zhang, "Research on the impact of financial development level the improvement of regional innovation and entrepreneurship ability," Economic Review Journal, vol. 421, no. 12, pp. 109-117, 2020.

[25] S. Y. Hou and L. R. Song, "Development of fintech, adiustment of financial structure and performance of enterprise innovation," China Business and Market, vol. 34, no. 4, pp. 100-109, 2020.

[26] X. M. Yang and J. Yang, "The incentive of digital finance on the innovation of small and medium -sized enterprises utility identification, mechanism and heterogeneity research," Journal of Yunnan University of Finance and Economics, vol. 37, no. 7, pp. 27-40, 2021.

[27] D. Jefferson, S. Stephan, and Y. Lance, "Trust and credit: the role of appearance in peer-to-peer lending," Review of Financial Studies, no. 8, pp. 2455-2483, 2012.

[28] R. Huang, X. B. Lai, D. N. Zhao, and Z. L. Tang, "Can digital finance ease the corporate financing difficulties? utility identification, feature mechanism, and regulatory evaluation," China Economic Studies, no. 1, pp. 52-66, 2021. 
[29] A. Fuster, M. Plosser, P. Schnabl, and J. Vickery, "The role of technology in mortgage lending," Review of Financial Studies, vol. 32, no. 5, pp. 1854-1899, 2019.

[30] X. G. Zhao, S. H. Zhong, and X. X. Guo, "Digital inclusive finance development, financial mismatch mitigation and enterprise innovations," Science Research Management, vol. 42, no. 4, pp. 158-169, 2021.

[31] J. Dai, Z. Yang, G. C. Liu, and C. H. Xu, "Bank competition, innovation resource allocation, and firm innovation output empirical evidence from the China industry census database," Journal of Financial Research, no. 2, pp. 51-70, 2020.

[32] X. J. Yi and L. Zhou, "Does digital financial inclusion significantly influence household consumption? evidence from household survey data in China," Journal of Financial Research, no. 11, pp. 47-67, 2018.

[33] L. T. Guo, "Corporate financialization, financing constraints and innovation investment-an empirical study based on Chinese manufacturing listed companies," Journal of Finance and Economics, no. 5, pp. 57-62, 2018.

[34] X. S. Ju, L. Di, and Y. H. Yu, "Financing constraints, working capital management and the persistence of firm innovation," Economic Research Journal, vol. 48, no. 1, pp. 4-16, 2013.

[35] L. Wang, J. J. Zhang, and X. Chen, "Shadow banking, small and medium-sized enterprises financing and deepening financial reform an empirical analysis based on SVAR model," East China Economic Management, vol. 29, no. 4, pp. 102-108, 2015.

[36] X. P. Ma, "The change of consumption in the digital economy: trends, characteristics mechanisms and model," Finance and Economics, no. 1, pp. 120-132, 2020.

[37] Z. Jiang and N. Li, "The impact of service innovation and manufacturing service on the enterprise performance," Science Research Management, vol. 36, no. 5, pp. 29-37, 2015.

[38] F. Guo, B. Zou, J. Y. Guo, and C. T. Dong, "Research on the mechanism of firm behavior effect on innovation capability and firm performance in the context of big data," Science of Science and Management of S.\&T.vol. 38, no. 4, pp. 126-136, 2017.

[39] H. Y. Zhai and Y. S. Liu, "Research on the relationship among digital finance development financing constraint and enterprise green innovation," Science \& Technology Progress and Policy, vol. 38, no. 17, pp. 116-124, 2021.

[40] J. Yang, M. Y. Xiao, and P. Lv, "Does digital inclusive finance promote the technology innovation of small and micro enterprises? An empirical study based on the data of China small and micro enterprise survey," Journal of Zhongnan University of Economics and Law, vol. 4, pp. 119-131, 2021.

[41] F. Guo, J. Y. Wang, F. Wang, T. Kong, X. Zhang, and Z. Y. Cheng, "Measuring China's digital financial inclusion: index compilation and spatial characteristics," China Economic Quarterly, vol. 19, no. 4, pp. 1401-1418, 2020.

[42] Z. L. Wen and B. J. Ye, "Analyses of mediating effects: the development of methods and models," Advances in Psychological Science, vol. 22, no. 5, pp. 731-745, 2014.

[43] T. Sun and J. Wen, "Financial intermediation, enterprise heterogeneity and technical innovation," Journal of Xi'an Jiaotong University, vol. 32, no. 1, pp. 23-28, 2012.

[44] F. X. Jiang, B. B. Shi, and Y. B. Ma, "Information releasers financial experience and corporate financial constraints," Economic Research Journal, vol. 51, no. 6, pp. 83-97, 2016.

[45] H. G. Li and Y. Z. Du, "Research on innovation network construction and its governance of innovative enterprises," Special Economic Zone, no. 1, pp. 294-296, 2009.
[46] L. L. Zhu, F. X. Wu, and W. Zhang, "Innovation behavior of state-owned enterprises in China:characteristic facts and the impact from private capital investment," Collected Essays on Finance and Economics, pp. 1-14, 2021.

[47] Z. Li and Y. H. Lu, "Do state-owned enterprises really lack innovation ability-a comparative analysis based on innovation performance of state-owned enterprises and private enterprises," Economic Theory and Business Management, no. 2, pp. 27-38, 2014. 